\title{
Your news in 140 characters: exploring the role of social media in journalism
}

\author{
Wilma Stassen
}

\begin{abstract}
"I saw on Facebook..." is a term frequently heard in conversations these days. This social network application, and others like it, was originally developed to help a person connect with friends and like-minded people. They have since evolved into powerful tools for communication that are being harnessed by the news media to interact with audiences. This article explores the use of social media in a local media organisation, and endeavours to determine its value to journalism.
\end{abstract}

Keywords: blogs, Facebook, interactive, Internet, online journalism, social media, social network, Twitter, Web 2.0. 


\subsection{Introduction}

'Journalism as it is, is coming to an end' (Deuze, 2007:141).

The Internet is fast changing the way people consume their news. This activity was previously limited to reading the newspaper or listening to a news bulletin on radio, or watching it on television. Today, however, audiences can get an "instant helping" of the latest news (literally minutes or hours old) on the Internet, or receive updates on their mobile phones, in their email inbox or on their social network pages (Momberg, 2009a).

Today's news consumers live in an interconnected world where information is ever more critical to their lives, and 'it is the task of journalism to convey that information' (Beckett, 2008:4). This means that journalism should reach beyond its conventional mediums - newspapers, TV and radio - to where the new audience is: in cyberspace. For news organisations to stay ahead in the field, they have to embrace new technology and adapt their products in ways that add value to what they do (Ludtke, 2009:4).

In South Africa, many traditional news organisations (print - newspapers and magazines - and broadcast - radio and TV) have created websites in addition to their conventional publications or programmes, where the audience have access to content from the original (traditional) product (Momberg, 2009b).

A recent trend in online news is not merely having a website on the Internet where users come to browse your content, but literally reaching out to your audience and delivering news updates through different channels on the Internet - known as social media (Gordon, 2009:7). In fact, the mantra for modern-day news organisations is to be "anywhere, anytime on any platform" (Picard, 2009:10).

The uptake of social media in news organisations is growing and today journalists are "romancing new communities by blogging and posting updates and stories on Twitter, YouTube and Facebook," (Emmett, 2008).

Recruiting new users on other channels is particularly important considering the constant decline in newspaper circulation figures over the last decade (Momberg, 2009b). Despite some tabloids and isiZulu newspapers that have shown growth in recent years, Momberg (2009b) points out

that five newspaper titles in the Western Cape region have shown a decline in circulation of 36.76 percent over the past decade. This trend is not restricted to the local news industry, with international stalwarts like the New York Times and the Chicago Tribune in financial straits as readers migrate online (Momberg, 2009b).

This decline in readership has lead to some traditional media viewing online publishing as a threat (Wright, 2004:3). Claims that online publishing will replace magazines, newspapers and books fuel this negative perception of the medium, yet "the internet holds a host of possibilities for those in these traditional media" (Wright, 2004:3). 
Ludtke (2009:4) argues that social media can bring greater depth and breadth to journalists' work. However, he states the negative perceptions those in traditional media have about the internet could deter them from reaping the benefits of social media for their users, and ,perhaps, even the profession.

\subsection{Research question}

This assignment aims to examine the role social media plays in the online news service, News24's, interaction with its audience. This study will pay particular attention to the two social networks Gordon (2009:7) calls the driving forces behind online communication, Facebook and Twitter. The study sets out to answer the following research question:

What role does social media play in News24's interaction with its audience, with particular focus on Facebook and Twitter?

\section{Context}

\subsection{Origin of online news}

Computers have been around since the 1940s when the first Electronic Numerical Integrator and Computer (ENIAC) - a 30-ton, room-sized computer - was built at the University of Pennsylvania in the United States (US) (Carlson, 2003:31). It took about 50 years from the invention of the first computer until information - and also news - began to be delivered primarily to computers in 1990. Teletext and videotex were the first kind of online journalism to develop between 1970 and 2000. Carlson (2003:32-35) defines teletext and videotex as follows:

- Teletext is a non-interactive system for transmission of text and graphics for display on a television set. Information is transmitted via a decoder or built-in chip.

- Videotex systems are interactive, computer-based systems that electronically deliver text, numbers, and graphics for display on a television set, video monitor, or personal computer. The data travels over telephone lines, two-way cable, computer networks or wireless data networks.

The Financial Times of London, the Post and Echo of Liverpool, and Eastern Counties Newspapers were the first to distribute news online via a videotex system in 1978, and in 1979 the first videotex system was launched commercially in the United Kingdom (UK) (Carlson, 2003:36). A similar system was launched in France in 1980, and in 1981 in the US.

Over the years, many videotex services were launched only to close down again for not being profitable. But there were some that persisted, and as the personal computer gained popularity, more and more people started making use of the videotex system. By the early 1990s computer online services were experiencing dramatic growth (Carlson, 2003:45).

The world wide web itself was created in 1990 when Tim Berners-Lee and colleagues at the European Centre for Particle Physics (CERN) developed the computer language that enabled users to navigate by simply clicking on underlined words called links. The language, called Hypertext Markup Language (HTML), is still the basis of web pages today (Carlson, 2003:49). 
The next development in online news was the computer bulletin board system, BBS - a software package that enabled personal computers to house a complete interactive online system. According to Carlson (2003:45), between 1990 and 1994, more than 30 US newspapers launched computer BBSs.

The first journalism site on the web was launched in November 1993 at the University of Florida College of Journalism and Communications, and on January 19, 1994, the Palo Alto Weekly in California, US, became the first newspaper to publish regularly onto the web (Carlson, 2003:49$50)$.

When the Tribune Company of Chicago announced it would offer a service on AOL (then one of a handful of world wide web services) in the early 1990s, it was the start of a new movement and other big titles, like Time Magazine and the New York Times followed. The trend picked up quickly, and by the end of 1995, some 330 US newspapers had some type of online service (Carlson, 2003:52).

Since then the world wide web has developed exponentially and is currently in the phase known as Web 2.0, which will briefly be discussed in the following section.

\subsection{Web 2.0}

The term Web 2.0 describes an ongoing transition of the world wide web from "a collection of websites to a fully-fledged computing platform serving web applications to end users" (Eneroth in Hitge, 2007:61). Web 2.0 is a "new wave of internet development offering a more dynamic online experience at low cost, using established software tools" (Eneroth in Hitge, 2007:61).

In the next segment the research focuses on online news in the South African market.

\subsection{Local online news websites}

During the 1990s, some South African news services followed the trend of their American counterpart and also established websites (Rossouw, 2005:215). The Mail \& Guardian was the first to launch an online news service in South Africa (and Africa) when it went online early in 1994 (Mail \& Guardian online, 2009). Although the uptake of online news media was slow at first, today tens of South African news services have established a presence online with News24, IOL News, Mail \& Guardian Online, Beeld and the Sowetan leading the market in terms of the amount of users who visit the website - the online equivalent of a newspaper's circulation figures (Nielsen, 2009).

In the next section we take a closer look at News24, which will serve as the case study for this assignment.

\subsection{News 24}

News24 was launched in October 1998 (Rossouw, 2005:215). Currently it is the largest online news website in South Africa with an average of over 1.2 million local users per month (Nielsen, 2009). 
For the first five years of its existence, News24's only interface was its website, where users could read stories and view photographs (Momberg, 2009a). In 2003, News24 in association with its pay TV partner, Multichoice, started broadcasting their news site on a channel of the satellite TV broadcaster, DSTV (Momberg, 2009a). Two years later, in 2005, they also launched a WAPsite, where users with Internet access on their mobile phones can browse News24 on their phones. Users on the WAPsite can also register to receive the latest news updates via SMS alert (Momberg, 2009a). In addition, News24 users can register for a web feed, known as an RSS (Really Simple Syndication) feed, and also receive news updates via email (Momberg, 2009a).

In 2008, News24 also started making use of social media and is currently active on the following platforms:

- Blogs

- Facebook

- Twitter

- Social bookmarking pages: Laaik.it, Yahoo, Google, Digg and Del.icio.us.

- YouTube

According to Momberg (2009a), News24 decided to make use of these channels in order to reach out to users that would not as a rule visit their website. 'We have to be on all these channels to try and find our audience there' (Momberg, 2009a).

In the next section each of the above-mentioned social media platforms will be discussed briefly.

\subsection{Social media}

Today's new culture is about connection and relationship. Social networks are humming because they fit the spirit of the time, not because they created the spirit of sharing. They're about listening to others and responding. They're about pursuing our interests because we know they will converge with the interests of others. The new culture values sharing information and being surprised by the experiences, knowledge and voices of others (Skoler, 2009:39).

Social media is a group of Internet-based applications that builds on the ideological and technological foundations of Web 2.0, and allows the creation and exchange of user-generated content (Kaplan \& Haenlein, 2009). It supports the democratisation of knowledge and information, transforming people from content consumers into content producers (searchenginewatch, 2009).

It is widely believed that social media is transforming the way in which people receive and share information. One of the major attributes to social networking is its high level of interactivity (Ludtke, 2009:4) that adds value through its ability to facilitate meaningful conversation with, 
and between users (Lowery, 2009:32). Picard (2009:11) argues that social media and blogs provide an opportunity for users to express themselves and connect with like-minded people:

These digital tools provide an easy (little to no cost) way for members of the public to take part in discussion with larger groups of people and draw attention to issues and topics that traditional news media might have overlooked (original brackets).

Beckett (2008:22) believes that not only is it 'more fun' to communicate through social media (compared to traditional media channels), but the interactivity also provide a sense of community 'that transcends anything offered by mainstream media.'

Social media have also permeated journalism. Overholser (2009:6) argues that the concept and profession of journalism is not turning into social media, but as professional communicators with an interest in public interest, journalists have to get in on the conversations taking place through social media. Skoler (2009:39) also believes that social media sites are not doing journalism, but notes that "sometimes breaking news shows up there", making it a valuable tool for journalists to find new story leads.

Picard (2009:11) reiterates this point and adds that through the use of social media, journalists can get information, ideas and feedback from their audiences. Through constant interaction with users journalists develop a different type of relationship than the "arms-length" connection created by traditional mass communication.

\subsubsection{Blogs}

Weblogs, shortened as blogs, as we know it today, were first developed in the early nineties and were designed to be 'Internet-based, personal publishing tools' (Hitge, 2007:1-2). Blogs make it possible for everyone with basic computer skills and access to the Internet, to publish onto the web. It is an online journal comprised of links and postings in reverse chronological order, so that the most recent posting appears at the top of the page (Gillmor, 2006:29).

Weblogs typically link to other websites and blog postings, and many allow readers to comment on the original post, thereby allowing audience discussions (Gillmor, 2006:29). Blogging is interactive by nature and the network of bloggers who read and comment on each other's blogs, are known as the blogosphere.

According to Cooper (2006:17-20) the blogosphere is proving to be a source of criticism for journalism, with bloggers using this platform to comment on, and critique articles in the press.

Blogging has also impacted on journalism in that regular citizens are increasingly performing 'random acts of journalism', having witnessed an event and writing about it on a blog (Goldfain \& Van der Merwe, 2006:105). Furthermore, journalists who work for mainstream media outlets have also entered the blogosphere by creating j-blogs - a cross between a column, a story and a journal (De Vries, 2008:6). 
News24 is closely linked to the blogging platform, Letterdash, but also has a section of the website dedicated to user-generated content. MyNews24 publishes letters, columns, articles, pictures and videos submitted by News24 users (Reece, 2009a).

\subsubsection{Facebook}

Facebook is a free global social networking website. Users create a personal profile which they can link to their friends' profiles. They can also send messages and update their personal profiles to notify friends about themselves. In addition, users can join networks organised by a city, region, organisation and more (Wikipedia, 2009). It has impacted on journalism in that media organisations create corporate profiles to which their audience link and receive regular updates on their own profiles.

News24 has a Facebook profile and also a Facebook headline application that Facebook members can install to receive news feeds to their individual profile pages (Momberg, 2009). By end November 2009, News24 had 670 fans linked to their Facebook profile (Facebook, 2009).

\subsubsection{Twitter}

Twitter is a free social networking and micro-blogging service that enables users to send and read messages (known as "tweets"). Subscribers also create a profile to which other subscribers link as "followers". Tweets are posts of up to 140 characters displayed on the author's profile page and delivered to the author's followers (Wikipedia, 2009).

The news media have tapped into this source by once again creating profiles to which audience members can subscribe. The news outlets send tweets - that may be a news update or type of microblog - to followers. Journalists also become followers of influential people who may give them tips on breaking news stories, and in fact, celebrity tweets have become the topic of news stories in itself.

News24 has also joined Twitter, and by the end of 2009, had 4,204 followers on this application (Twitter, 2009).

\subsubsection{Social bookmarking}

Social bookmarking is a method of tagging a website in order to share, organise, search or manage web resources (Nations, 2009). With social bookmarking you can save your favourite websites, pass them on to friends and also look at what other people have found interesting enough to tag. Social bookmarking platforms like the website Digg, focus on social bookmarking of news-related items in particular. These types of websites often feature breaking news headlines and bloggers discuss current news items (Nations, 2009).

News24 has linked the local social bookmarking platform Laaik.it, as well as the international sites Yahoo!, Google, Digg and Del.icio.us, to their website (Momberg, 2009c).

\subsubsection{YouTube}

YouTube is a video- sharing website on which users can upload, share and view videos. 
News24 has published videos onto YouTube in order to create an awareness of their brand on this channel (Momberg, 2009a). However, compared to the other mediums, mentioned above, News24 is not very active on this channel.

\subsection{The digital divide}

An important issue to consider around social media, especially in a developing society such as our own, is the fact that it is reserved for a privileged minority who has access to the Internet, and who is somewhat computer-savvy.

A large disparity between the technology haves and technology have-nots is evident, ultimately turning the Internet into an exclusive medium that can be accessed only by those with money (Berger in Goldfain \& Van der Merwe et al, 2006:110).

Frissen (2005:272) also highlights the threat of a dichotomy, arguing that it may not only create social inequality, but also reinforce existing inequalities against those that are already marginalised - the poor, unemployed, et cetera.

Goldfain and Van der Merwe (2006:110) further argue that because of this inequality to access '...it is not a truly democratic medium in Africa' (in reference to the social media platform of blogs).

\section{Theoretical frameworks}

The broad theoretical frameworks of this research assignment are the information society and media evolution theories.

\subsection{Information society}

The information society paradigm concerns itself with new media, information and communication technology (ICT) (Fourie, 2001:252). Although there is no clear definition of "information society", it generally refers to a greater flow of information due to electronic networks and computerisation (McQuail, 2005:105).

A central feature of new media - the media of the information society (Fourie, 2001:252) - is its two-way capability. Rice (in Lievrouw \& Livingstone, 2001:21) defines new media as computerfacilitated connectivity and interactivity between users and information. A central point of the information society theory is the interconnectedness it offers users on a global level (Fourie, 2001:253). New media offers a higher degree of interactivity, sociability, autonomy, playfulness and personalisation than earlier forms of media (Fourie, 2001:252).

The information society theory also describes a greater dependence on, and trust in, ICT in order to lead a normal life. Fourie (2001:253) uses the example of banking, shopping and entertainment as activities that are being permeated by computerisation. 


\subsection{Media evolution theory}

Stöber's (2004:483) media evolution theory suggests that new media is not merely the consequence of technical invention, but originates from a two-stage process of inventing and social institutionalising.

The invention phase is often considered the improvement of something old: new features are adapted for old purposes (Stöber, 2004:488).

According to Stöber (2004:485), "institutionalisation" of an invention involves the discovery of new possibilities of communication, formatting new media functions and adapting new media, developing new economic models, and acceptance of new media by creating a new political framework and a new legal order for new media.

The stage of "diffusion" follows institutionalisation and entails the distribution of new media which then confirms the successful emergence of new media (Stöber, 2004:485).

Section three involved the theoretical frameworks of this research article. In the next segment, the research design and methodology will be discussed.

\section{Research design and methodology}

The purpose of science is to study and explain human reality in an authoritative fashion, and in such a way that it acquires value and use for mankind. In the scientific study of communication, we emphasise a specific part of this reality with its constituent parts... (Du Plooy, 1997:1-2).

This study aims to contribute to the body of knowledge on the topic of social media. The social relevance of this research is based on the growing popularity of social media within news organisations (Gordon, 2009:7), and particularly the interactivity and interconnectedness it creates between media organisations and users. Other motivations for the research are its chronological relevance, and the fact that very little research has been done on social media in South Africa.

The qualitative research methodology will be used for the study. According to Du Plooy (1997:33), qualitative research often provides a deeper insight into a topic and allows a researcher to study a phenomenon from an insider's point of view.

A case study into a South African online publication's application of social networking tools was chosen as the research design for this study. Case studies are studies that are usually qualitative in nature and aim to provide an in-depth description of a small number of cases (Mouton, 2005:149).

In qualitative research, there are four main modes of enquiry - field research, survey research, content analysis and experimental research (Du Plooy, 1996:vi). Survey research was chosen for 
this study. Du Plooy (1997:127) explains that surveys are used to 'collect information from a group of people to describe their abilities, opinions, attitudes, beliefs and/or their knowledge with regard to a particular topic or issue.' The cross-sectional survey method, using questionnaires, was used to collect data.

Sampling is an important factor in survey research. A basic principle of sampling is that a sample should be representative of the population from which it is selected and all members of a population must have an equal chance of being selected for the sample (Babbie, Mouton, Vorster \& Prozesky, 2007:173). For the purpose of this research, the following three staff members of News24 and a former staff member of 24.com completed the survey:

- Jannie Momberg - Chief Editor

- Cathryn Reece - Community Editor

- Estrelita Moses - News Editor

- Alistair Fairweather - former Social Media Manager at 24.com

These four participants were not chosen according to the strict requirements of sampling, however. They represent, instead, the only News24 and 24.com staff members involved in the decision-making and practice of social media for News24.

The survey was sent to the above-mentioned participants via email, who completed the survey and returned it via email to the researcher.

\section{Research results}

The undertaking of this assignment set out to explore the role of social media in journalism, with the express intent of focusing on the South African digital news service, News24. With this in mind, a survey questionnaire was compiled in order to conduct the research for this assignment.

\subsection{Social media}

The News24 webpage, MyNews24, is, according to day news editor, Estrelita Moses, designed with the intent of serving as a platform for users to communicate with News24 editors and the News24 community (2009),. With that, News24 makes wide use of the two social media applications, Facebook and Twitter, to interact with users (Moses, 2009).

Jannie Momberg is the chief editor for News24. He believes it is difficult to foresee what the long-term impact of social media on the media will be, but predicts that it will probably become more integrated in the day-to-day life of the media (Momberg, 2009c).

\subsection{How does News24 apply Facebook and Twitter?}

News24 uses the social media platforms Facebook and Twitter to communicate with its audience even when they are not browsing the News24 website, and in so doing, they are constantly building the brand (Momberg, 2009c). Momberg believes that these functions make it easier for News24 users to share content with others, adding that 'these days, the most authoritative sources are more often than not, someone you know and trust.' 
Facebook and Twitter members who browse News24 can log onto their Facebook and Twitter profiles via the News24 website, where they can then share News24 content with Facebook friends, or Twitter followers (Momberg, 2009c).

According to News24's community editor, Cathryn Reece (2009b), News24 uses Facebook and Twitter to reach out to the community 'with a human touch.' Headlines are automatically put out on both platforms, and staff members also communicate and respond to users on these platforms. In Reece's view, News24 is using social media to build their brand, and also to source information (Reece, 2009b).

Moses (2009) adds that by using these platforms, users feel they belong to a community and are active in the story-generating process.

\subsection{The advantages of social media for News24?}

Both Momberg (2009c) and Reece (2009b) believe that the main advantages of integrating social media into an online news service is brand and community building, as well as using these resources as a source for story leads, and in some instances, also references. These tools also provide real-time feedback from users (Reece, 2009b).

In Moses' (2009) view, one of the main advantages of social media is that new information/stories are available far quicker over these platforms (especially Twitter) compared to traditional sources, such as news wires. 'It [social networking] also helps to build community and brand loyalty' (Moses, 2009).

The former social media manager for 24.com, Alistair Fairweather (2009), identified the following advantages of social media: audience research; story generation; content promotion; community building; customer service; and sustaining and broadening attention.

\subsection{Social networking and journalism}

Momberg (2009c) believes that there is a major role to be played by social networking in modern-day journalism. 'It is even more important in online journalism where a story is never finished - it is more of a process - so new updates/tips are valuable to keep the story going' (Momberg, 2009c).

Momberg (2009c) also firmly believes in the marketing/promoting possibilities social media offers an organisation.

According to Reece (2009b), social networking has an important role to play in journalism as it serves as a source of news and information. Constant feedback from the audience through these networks' interactive functions is also a boon to journalism (Reece, 2009b). Fairweather (2009) concurs saying that social networks 'are excelling for in-depth research on what ordinary people feel and think.' 
Moses (2009) also thinks that social media has an important place in journalism, but instead of using it as a tool for sourcing information she believes it can also be used to disseminate news: 'People want information in short, sharp bursts - and as quickly as possible' (Moses, 2009). Moses (2009) uses the example of a journalist reporting on a court case via Twitter, while the court is still in session. 'The user gets up-to-date info without having to wait' (Moses, 2009).

\subsection{The future of social media in journalism}

Momberg (2009c) believes that this is an interesting cross-over period for the media, and that the Internet is playing a key role in democratising the news media.

He argues that the competition online is "infinite" as a news website competes with every other news website on the Internet, where in the past, a newspaper only contended with publications in the same region. 'Add to that the power of social media networks to distribute and share content, it is obvious the old media model has been smashed.'

Some media organisations are even contemplating erecting pay walls around their content, and Momberg (2009c), thinks that it will be interesting to see which media models will survive five to 10 years down the line. 'I suspect pay walls will not be part of the solution.'

Reece (2009b) believes that although trends may come and go, social media is here to stay. 'The Internet has become a personal space, so no matter what traditional news organisations do online, we have to realise our content is competing with the personal. Instead of arguing over space, rather work with the space to leverage new audiences' (Reece, 2009b).

In Moses' (2009) view, social media is becoming a powerful tool as users become more involved in the news process. In fact, many important news stories have broken on the social platform Twitter, and Moses refers in particular to a case in Iran (where traditional news sources are restricted) where a woman's death received international attention after reports of maltreatment by the police came to light through Twitter reports (Moses, 2009).

Fairweather (2009) contends that in the not-too-distant future, all journalism and media will be intimately tied into social media (and vice versa).

There will be no real distinction between social media and media as a whole...no story will exist in isolation anymore - the community that orbits that story will have significant influence over debate. This means that the neat hierarchy/separation of journalism and society will continue to blur and break down. This will mean that news organisations will probably change quite radically into decentralised content curators and vetters, rather than content creators (Fairweather, 2009).

\section{Conclusions}

Results from the study show little doubt that social media has an important role to play in the future of journalism. 
The respondents identified various uses of social media for this news organisation: it is used to distribute information (albeit micro-stories that only highlight one or two points); it is a source of story ideas and information; it provides feedback from users; it serves as a platform to promote the news organisation and it helps build a community of users who feel connected to the news organisation.

From the study it is evident that social media facilitates a type of journalism in which the audience is much more involved in the news-creation process, where feedback happens in realtime and users have the opportunity to interact with each other. This feedback and interaction could potentially create a richer news experience for the user, especially compared to traditional media outlets where one-way communication mostly took place.

Fears about social media replacing journalism are unfounded. Although news organisations use it to send out news flashes, the tool as it is at the moment, cannot facilitate well-researched, unbiased and informed reporting - and it is not meant to. The real value of social media to journalism lies in its interconnectedness. By logging on to the right channels, a news organisation can have an "inside informant" in every sphere of society helping them to find the latest information, while at the same time providing a platform on which it can converse with its audience on the topic.

A way forward is for traditional news organisations to realise the value of social media, and instead of competing with it for the user's attention, embracing it and using it to their advantage as News24 has done.

\section{Author details}

Wilma Stassen, [wilma.stassen@sa.24.com], is an MPhil Journalism student at the Department of Journalism at Stellenbosch University.

Contact details:

402 Markev Court, Tamboerskloof Avenue, Cape Town, 8000

Tel: +214688140

Fax: +214688200 .

\section{References}

Allan, S. 2006. Online News: Journalism and the Internet. Open University Press: Berkshire.

Babbie, E., Mouton, J., Vorster, P. \& Prozesky, B. 2007. The practice of social research. Cape Town: Oxford University Press Southern Africa.

Beckett, C. 2008. SuperMedia - saving journalism so it can save the world. West Sussex: Blackwell Publishing.

Carlson, D. 2003. The history of online journalism. In: Kawamoto, K. 2003. Digital journalism emerging media and the changing horizons of journalism. Oxford: Roman and Littlefield Publishers. Pp. 31-57. 
Cooper, S.D. 2006. Watching the watchdog - bloggers as the Fifth Estate. Washington: Marquette Books.

Deuze, M. 2007. Media work - digital media and society series. Cambridge: Polity Press.

Du Plooy, G.M. (Ed.). [1995] 1997. Introduction to communication: Course Book 2 communication research. Kenwyn, South Africa: Juta.

De Vries, F. 2008. Blogs in the mainstream media: an exploration of a code of ethical conduct for j-bloggers at Die Burger Western Cape. MPhil (Journalism) thesis, University of Stellenbosch, South Africa.

Emmett, A. 2008. Networking news: traditional news outlets turn to social networking Web sites in an effort to build their online audience. American Journalism Review. Gale.

Facebook. 2009. News24's profile page on Facebook. www.facebook.com. Accessed: 2002-2611.

Fairweather, A. 2009. Personal email to the author from alistairf@gmail.com. Received: 20093011.

Fourie, P.J. (Ed.) 2001. Media Studies. Volume One. institutions, theories and issues. Lansdowne: Juta.

Frissen, V. 2005. The myth of the digital devide. In: Zerdick, A., Picot, A., Schrape, K., Burgelman, J., Silverstone, R., Feldmann, V., Wernick, C. \& Wolff, C. E-merging media communication and the media economy of the future. Berlin: Springer: Pp. 271-284.

Gillmor, D. 2006. We the media - grassroots journalism by the people, for the people. Sebastopol: O'Reilly Media.

Goldfain, K. \& Van der Merwe, N. 2006. The role of the political blog: the case of www.commentary.co.za. Communicare: Pp. 103-124.

Gordon, R. 2009. Social Media: the ground shifts. In: Nieman reports, finding a good fitjournalism and social media.

Hitge, L. 2007. The dog sat on the blog: an overview of how the weblog medium can be used in education. MPhil (Journalism) thesis, University of Stellenbosch, South Africa.

Lievrouw, L. \& Livingstone, S. (Ed.) 2002. The handbook of new media. London: Sage.

Lowery, C. 2009. An explosion prompts rethinking of Twitter and Facebook. In: Nieman reports, finding a good fit-journalism and social media. 
Ludtke, M. 2009. Let's talk: journalism and social media. In: Nieman reports, finding a good fit - journalism and social media.

Mail \& Guardian online. 2009. Mail \& Guardian online homepage. www.mg.co.za. Accessed: 2009-12-09.

McQuail, D. 2005. McQuail's mass communication theory. (Fifth edition). London: Sage.

Momberg, J. 2009a. Personal interview conducted on 10 February 2009. Green Point, South Africa. Copy of notes available from the author.

Momberg, J. 2009b. Online news - presentation to Media24's Journalism Academy.

Momberg, J. 2009c. Personal email to the author from Jannie.Momberg@sa.24.com. Received: 2009-11-24.

Moses, E. 2009. Personal email to the author from estrelita.moses@sa.24.com. Received: 200911-03.

Mouton, J. [2001] 2005. How to succeed in your Master's \& Doctoral Studies - a South African guide and resource book. Pretoria: Van Schaik Publishers.

Nations, D. 2009. Social Bookmarking 101 - What is social bookmarking and how can it help me? About.com. Accessed: 2009-11-20.

Nielsen Online Net Rating Service. 2009. Nielsen home page: http://secure.netratings.com. Accessed: 8 November 2009.

Overholser, G. 2009. What is journalism's place in social media? In: Nieman reports, finding a good fit-journalism and social media.

Picard, R.G. 2009. Blogs, Tweets, Social Media, and the News Business. In: Nieman reports, finding a good fit-journalism and social media.

Reece, C. 2009a. Personal email to author from cathryn.reece@news24.com. Received: 2009-0218.

Reece, C. 2009b. Personal email to author from cathryn.reece@news24.com. Received: 1 December 2009.

Rossouw, A. 2005. Journalism and the Internet. In: Hadland, A. (Ed.) 2005. Changing the Fourth Estate: essays on South African journalism. HSRC. Pp. 213-220.

Searchenginewatch. 2009. http://searchenginewatch.com. Accessed: 2009-11-26. 
Skoler, M. 2009. Why the news media became irrelevant - and how social media can help. In: Nieman reports, finding a good fit - journalism and social media.

Stöber, R. 2004. What media evolution is - a theoretical approach to the history of new nedia. In: European Journal of Communication. Sage: London. Pp. 483-505.

Twitter. 2009. News24's profile on Twitter. www.twitter.com. Accessed: 2009-11-15.

Wikipedia. 2009. Wikipedia homepage. www.wikipedi.org. Accessed: 2009-11-15.

Wright, B. 2004. The looking glass - a comparative case study of the way in which technology and health print publications use the internet. MPhil (Journalism) thesis, University of Stellenbosch, South Africa. 